\title{
Nature of the synergy between Brønsted and Lewis acid sites in Sn-Beta zeolites for polyoxymethylene dimethyl ethers synthesis
}

\author{
Christophe J. Baranowski, ${ }^{[a]}$ Maneka Roger,${ }^{[a, b]}$ Ali M. Bahmanpour, ${ }^{[a]}$ Oliver Kröcher ${ }^{\text {*a, b] }}$
}

\begin{abstract}
The role of Lewis and Brønsted acid sites, and their potential synergy remains ambiguous for the production of polyoxymethylene dimethyl ethers (OME), which are suitable as Diesel substitute. Here, we studied this synergistic effect using a series of BEA zeolites with various degrees of Brønsted and Lewis acidity. Lewis acidity was introduced in dealuminated zeolites by $\mathrm{Sn}$ grafting in dichloromethane. These sites were only active in paraformaldehyde decomposition, OME growth, and acetalization. Brønsted acid sites arising from bridging hydroxyl groups were active for all reaction steps, and notably for trioxane ring-opening and dissociation to formaldehyde (FA), which did not occur on Lewis acid sites. Presence of both Lewis and Brønsted acid sites led to a fourfold increase in turnover frequency and a significant decrease of byproduct formation compared to the parent zeolite during $\mathrm{OME}$ synthesis from $\mathrm{OME}_{1}$ and trioxane. The synergistic effect between both types of acid sites is explained by FA insertion on Lewis acid sites leading to OME growth. Interaction between tetrahedral $\mathrm{Sn}$ and the carbonyl group of FA resulted in an activated carbonyl bond, which is likely to be the initial step for insertion of FA into OME.
\end{abstract}

\section{Introduction}

The transition to a carbon-free economy will lead to unprecedent changes in the transportation sector. However, Diesel engines will continue to power a large share of the vehicles in the near-future due to their high thermal efficiency and energy density, which are key requirements for heavy-duty transport. Diesel consumption is expected to grow between 46 and $200 \%$ compared to its 2010 level during the next four decades, according to the World Energy Council. ${ }^{[1]}$ Meanwhile, air pollution has reached alarming levels in large cities forcing governments to adopt more stringent emission standards. In this context, polyoxymethylene dimethyl ethers (OME) have recently gained attention as a new type of Diesel additive or substitute due to their appealing properties. ${ }^{[2,3]}$ When blended with Diesel fuel, they reduce the level of soot emission with a concomitant increase in combustion efficiency. ${ }^{[4-6]}$ Moreover, their usage in diesel-powered cars only require slight engine modifications. ${ }^{[4]}$ Finally, they can be produced from

[a] C. J. Baranowski, A. M. Bahmanpour, F. Héroguel, J. S. Luterbacher, O. Kröcher

Institute of Chemical Sciences and Engineering, École polytechnique fédérale de Lausanne (EPFL),

Route cantonale, 1015 Lausanne, Switzerland

[b] O. Kröcher

Paul Scherrer Institut

5232 Villigen PSI, Switzerland

oliver.kroecher@psi.ch; Tel +41 (0)56 3102066

Supporting information for this article is given via a link at the end of the document. methanol which could be a future platform molecule synthesized from $\mathrm{CO}_{2}$ or biomass. ${ }^{[7,8]}$

The large-scale implementation of OME requires stable and active catalysts. Acidity is essential for OME synthesis and various solid acids have already been used as catalysts: acidic resins, ${ }^{[9,10]}$ zeolites $^{[11-13]}$ or other aluminosilicate-based materials ${ }^{[14,15]}$. Different synthesis routes exist depending on the oxymethylene and oxymethyl- sources: ${ }^{[16]}$ dimethoxymethane $\left(O M E_{1}\right)$, methanol or dimethyl ether, reacts with trioxane (TRI), formaldehyde (FA) or paraformaldehyde (PF) to form a SchulzFlory (SF) distribution of OME. The anhydrous route demonstrated the highest OME yield, but synthesis from methanol and FA reduces production complexity. ${ }^{[17,18]}$

Two reaction mechanisms were reported in the literature for OME synthesis: initiation, growth and termination (IGT) or sequential addition. ${ }^{[16,19-21]}$ The reactants and catalyst used determine which mechanism will prevail. The IGT mechanism is illustrated in Scheme 1. Initiation happens through the generation of a carbocation or a hemiformal intermediate. In the anhydrous route, $\mathrm{OME}_{1}$ forms a carbocation on a Brønsted site, whereupon methanol is released. Alternatively, methanol reacts rapidly with FA to generate a hemiformal. Growth occurs then by insertion of FA units into the above mentioned intermediates. ${ }^{[21]} \mathrm{FA}$ units can be generated from the decomposition of TRI or PF, but insertion of TRI into OME has also been reported. ${ }^{[21]}$ In their intermediate carbocation form, two OME can also exchange FA units (transacetalization reaction). Finally, termination occurs when methanol reacts with a hemiformal to produce OME and water (acetalization reaction). In the anhydrous route, the termination reaction is the reverse reaction of the initiation. The other reaction mechanism proposed is the sequential addition, which is similar to the growth step of IGT, except that OME are not in an intermediate form. ${ }^{[12]}$

Scheme 1. OME synthesis following the IGT mechanism from methanol or $\mathrm{OME}_{1}$

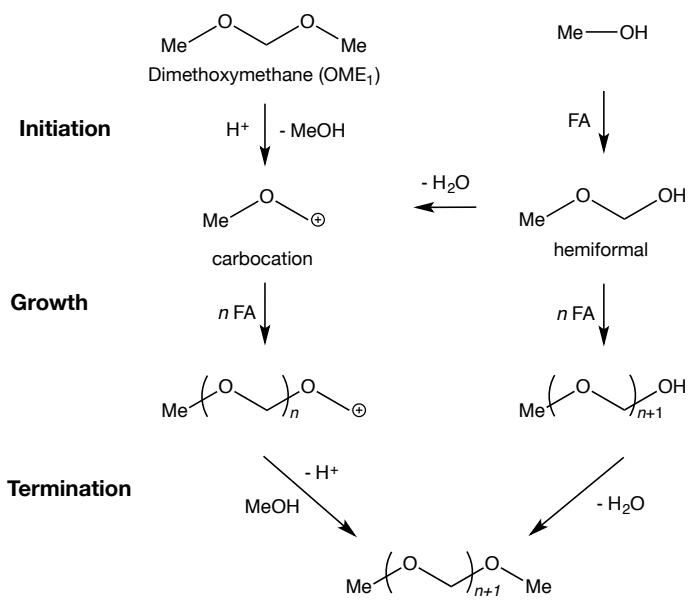


Various studies demonstrated that strong Brønsted acidity was required for OME synthesis. ${ }^{[22,23]}$ Others showed that Lewis acidity could also catalyze OME production. ${ }^{[24,25]}$ However, these studies implied a wide range of reactants and catalysts, which prevents general conclusions to be drawn.

Liu et al. recently reported the existence of a synergy between Lewis and Brønsted acid sites for the synthesis of OME from PF and $\mathrm{OME}_{1}{ }^{[26]}$ However, their suggested reaction mechanism does not explain the nature of this synergistic effect. Thus, the precise role of Brønsted and Lewis acid sites, and their potential synergy remains ambiguous. Therefore, the goals of this study were twofold. First, we sought to acquire a deeper understanding of the type of acidity involved in the different OME synthesis steps. Second, we aimed at investigating the nature of the synergy between Lewis and Brønsted acid sites. These objectives were pursued by synthetizing a series of BEA zeolites with various amounts of Brønsted and Lewis acid sites (Scheme 2).

Lewis acidity was introduced in the zeolite framework via Sn incorporation by grafting in dichloromethane, as it was shown to lead to high and controllable Sn content with little extra-framework Sn. ${ }^{[27]}$ These catalysts were then applied in several reactions for OME synthesis. The results of this work demonstrated that Brønsted sites were active in all steps of OME synthesis while Lewis acid sites were only active in OME growth, PF decomposition and hemiacetal acetalization. Our study also confirmed the synergy between Brønsted and Lewis sites, and identified FA insertion in OME on tetrahedral $\mathrm{Sn}$ as the key step involving Lewis sites.

\section{Results}

\section{Physico-chemical characterization of the catalysts}

Neither dealumination, nor Sn grafting affected the zeolite structure, as all XRD patterns were consistent with the BEA topology (Fig. S1, Supplementary information). Furthermore, no $\mathrm{SnO}_{2}$ phase was detected, which rules out the possibility of the presence of extra-framework crystallites larger than $3 \mathrm{~nm}$.
Scheme 2. Treatments applied to parent H-Beta zeolite (H-Beta-P) for the synthesis of a series of zeolites with varying amounts of Brønsted and Lewis acid sites.

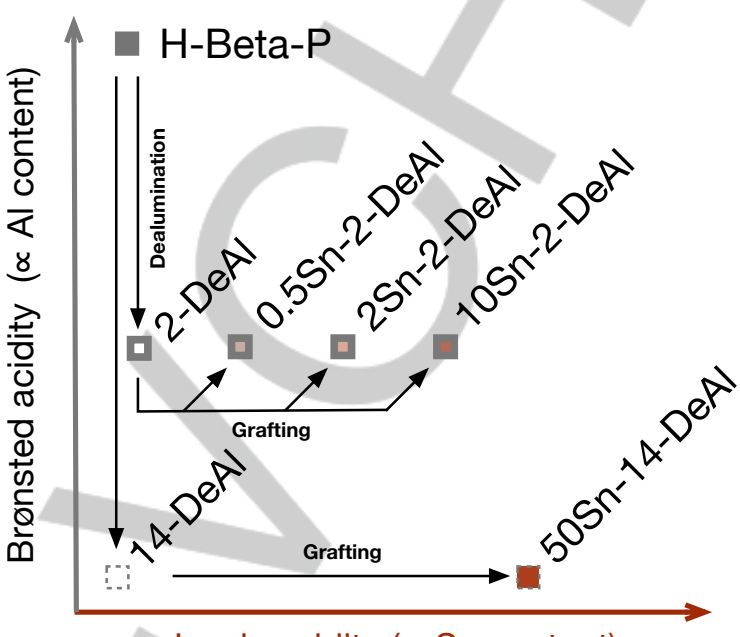

Lewis acidity ( $\propto$ Sn content)

The textural properties were assessed by $\mathrm{N}_{2}$ physisorption measurements (Table 2) and no structure amorphization was identified following the treatments of the zeolites.

The protonated parent zeolite (H-Beta-P) displayed initial mesoporosity (172 $\left.\mathrm{m}^{2} \cdot \mathrm{g}^{-1}\right)$, which increased with the dealumination treatment to 189 and $192 \mathrm{~m}^{2} \cdot \mathrm{g}^{-1}$ for 2-DeAl and 14DeAl, respectively. Dealumination also induced a slight increase in H-Beta-P microporous surface area $\left(\mathrm{S}_{\text {micro }}\right)$ from $356 \mathrm{~m}^{2} \cdot \mathrm{g}^{-1}$, to 379 and $400 \mathrm{~m}^{2} \cdot \mathrm{g}^{-1}$ for 2-DeAl and 14-DeAl, respectively. Sn grafting resulted in a small decrease in $S_{\text {micro, while the }}$ mesoporous surface area decreased with increasing the Sn grafting concentration.

Table 1. Textural parameters, composition and acidity of the catalysts.

\begin{tabular}{|c|c|c|c|c|c|c|c|c|c|}
\hline \multirow[b]{2}{*}{ Sample } & \multicolumn{3}{|c|}{ Surface area $\left(m^{2} \cdot g^{-1}\right)$} & \multicolumn{2}{|c|}{ Volume $\left(\mathrm{cm}^{3} \cdot \mathrm{g}^{-1}\right)$} & \multicolumn{3}{|c|}{ Composition (wt. \%) } & \multirow[b]{2}{*}{ Acidity $\left(\mathrm{mmol} \cdot \mathrm{g}^{-1}\right)$} \\
\hline & $\mathrm{BET}$ & Micro $^{[a]}$ & $\mathrm{Meso}^{[\mathrm{b}]}$ & Micro $^{[a]}$ & Meso $^{[b]}$ & $\mathrm{Al}$ & $\mathrm{Si}$ & Sn & \\
\hline H-Beta-P & 543 & 356 & 172 & 0.155 & 0.536 & 3.50 & 41.40 & 0 & 0.880 \\
\hline 2-DeAl & 589 & 379 & 189 & 0.166 & 0.655 & 0.35 & 43.31 & 0 & 0.196 \\
\hline 14-DeAl & 609 & 400 & 192 & 0.174 & 0.638 & 0.05 & 43.41 & 0 & 0.081 \\
\hline $0.5 \mathrm{Sn}-2-\mathrm{DeAl}$ & 554 & 348 & 188 & 0.150 & 0.694 & 0.35 & 43.46 & 0.28 & 0.187 \\
\hline 2Sn-2-DeAl & 567 & 361 & 184 & 0.158 & 0.655 & 0.35 & 43.78 & 0.63 & 0.193 \\
\hline 10Sn-2-DeAl & 556 & 357 & 182 & 0.156 & 0.621 & 0.35 & 43.55 & 1.09 & 0.225 \\
\hline 50Sn-14-DeAl & 558 & 352 & 183 & 0.152 & 0.610 & 0.05 & 45.00 & 3.06 & 0.230 \\
\hline
\end{tabular}

[a] Calculated based on the t-plot method. [b] Calculated based on the BJH method using the adsorption branch. 


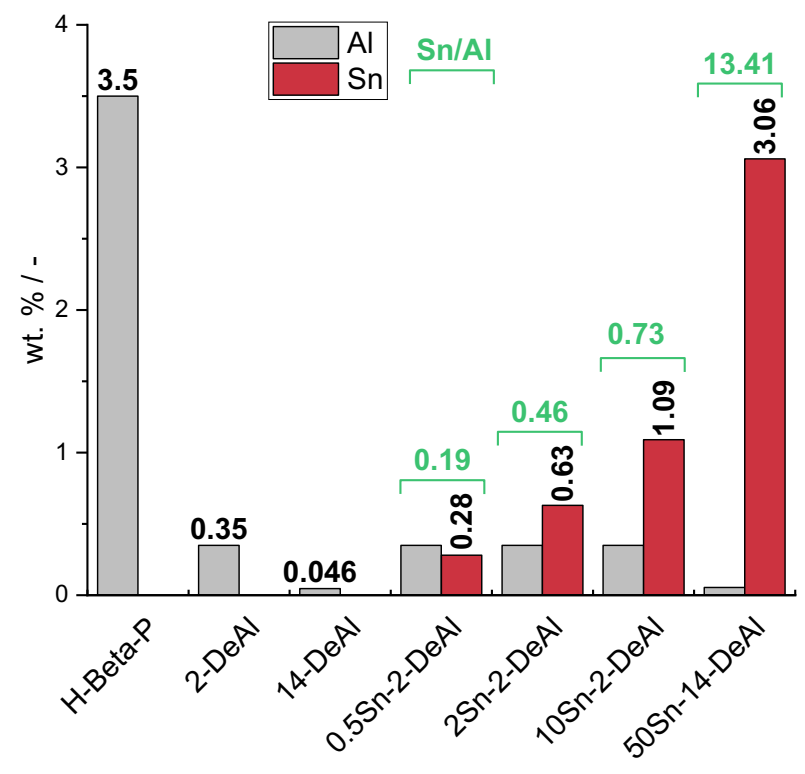

Fig. 1. ICP-OES analysis of the various catalysts.

ICP-OES analysis (Fig. 1) confirmed that the aluminum concentration decreased with an increasing dealumination extent, changing from 3.5 to $0.35 \mathrm{wt}$. \% with partial dealumination. Complete dealumination led to removal of almost all Al content (0.046 wt. \% left). Increasing Sn loadings were achieved for the partially dealuminated, Sn-modified samples with increasing $\mathrm{SnCl}_{4}$ concentration during $\mathrm{Sn}$ grafting. The highest $\mathrm{Sn}$ content of 3.06 wt. \% was reached with $50 \mathrm{Sn}-14 \mathrm{DeAl}$, which thus mainly contained $\mathrm{Sn}$ compared to $\mathrm{Al}$ (Sn/Al molar ratio of 13.41).

DRIFT spectroscopy confirmed that $S n$ was incorporated into the zeolite framework in vacant silanol nests (Fig. S2). Aluminum

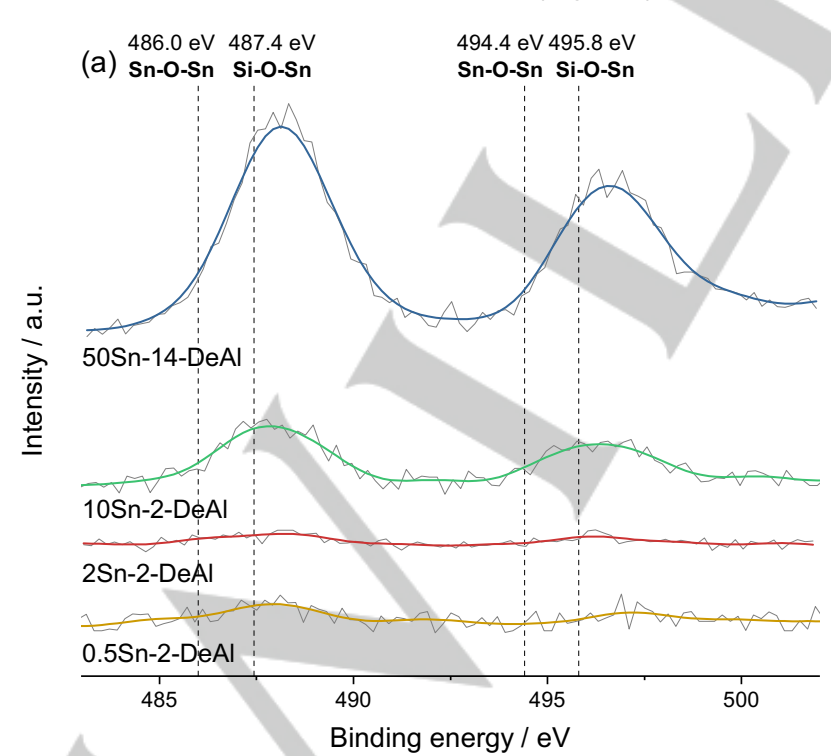

extraction led to an increase in the terminal $\mathrm{Si}-\mathrm{OH}$ and internal silanol nest signals, respectively at 3740 and ca. $3500 \mathrm{~cm}^{-1} .{ }^{133]}$ The silanol nest signal decreased with increasing Sn loading, while the isolated silanol signal did not vary. The Sn distribution in the zeolite framework was also examined by HAADF-STEM imaging with elemental mapping (Fig. S3). Sn was well dispersed in all Sn-containing samples and no aggregates were observed. Next, Sn coordination states in the Sn-modified samples were studied by XPS (Fig. 2a). Overall, the two signals derived from the $3 d_{5 / 2}$ and $3 d_{3 / 2}$ were close to previously reported values corresponding to tetrahedrally coordinated framework Sn (487.4 $\mathrm{eV}$ and $495.8 \mathrm{eV}$ ). ${ }^{[34]}$ No signal caused by octahedral $\mathrm{Sn}$ was detected at 486.0 and $494.4 \mathrm{eV}$ which shows that no extraframework $\mathrm{Sn}$ was present in these catalysts. Diffuse reflectance UV-Vis (DRUV) spectroscopy also confirmed that no extraframework Sn was present as no signal was obtained around 280 $\mathrm{nm}$, which has been attributed to extra-framework $\mathrm{SnO}_{2}$ (Fig. 2b). ${ }^{[35]}$ The main signal was located between 218 and $235 \mathrm{~nm}$, arising from the ligand-to-metal charge transfer from the surrounding $O$ atoms to the unoccupied orbitals of isolated $\mathrm{Sn}^{\mathrm{IV}} \cdot{ }^{[36]}$

The Sn-containing samples were further characterized by ${ }^{119} \mathrm{Sn}$ magic angle spinning NMR (MAS-NMR) (Fig. S4a and b). 50Sn14-DeAl, which contained the highest $\mathrm{Sn}$ load, displayed a peak centered at $-616 \mathrm{ppm}$, which corresponds to the hydrated form of $\mathrm{Sn}$ in a tetrahedral coordination in the framework lattice.$^{[37]}$ Due to their smaller loadings and the low abundance of ${ }^{119} \mathrm{Sn}$, for the partially dealuminated, Sn-modified samples Carr-PurcellMeiboom-Gill (CPMG) MAS-NMR analysis were applied. This resulted in a sharper peak located at -643 and $-650 \mathrm{ppm}$ for $2 \mathrm{Sn}-$ 2-DeAl and 10Sn-2-DeAl, respectively. This signal is attributed to hydrated, hydrolyzed open Sn sites, which are expected after Sn grafting on a dealuminated zeolite. ${ }^{[27,37]}$

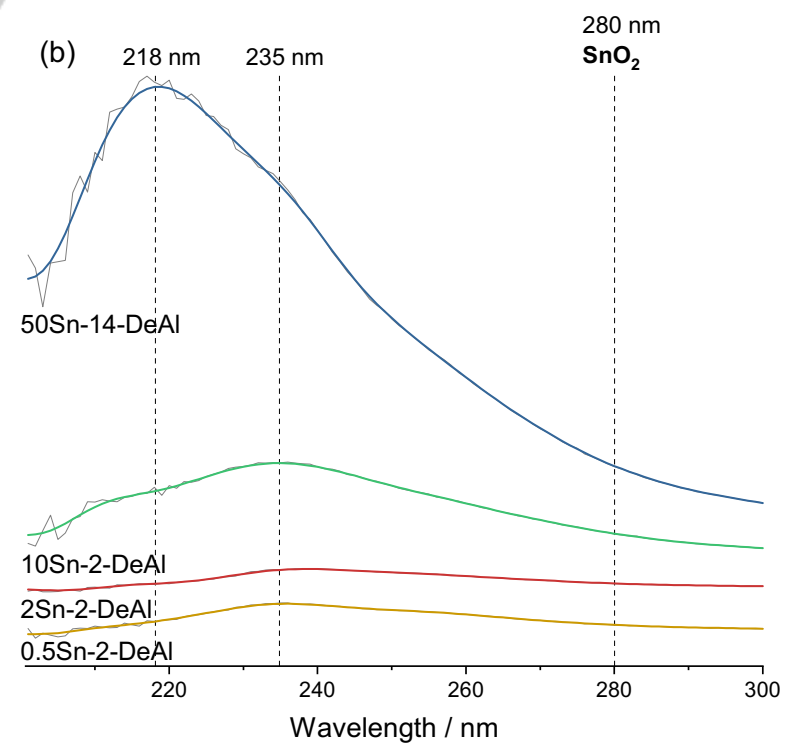

Fig. 2. Analysis of the Sn-containing catalysts by (a) XPS and (b) in-situ DRUV spectroscopy at $400{ }^{\circ} \mathrm{C}$ under a He flow of $20 \mathrm{~mL} \cdot \mathrm{min}^{-1}$. The gray and colored lines correspond to the original and smoothed curves, respectively. Smoothing was performed using a FFT filter (5 points). 
(a)

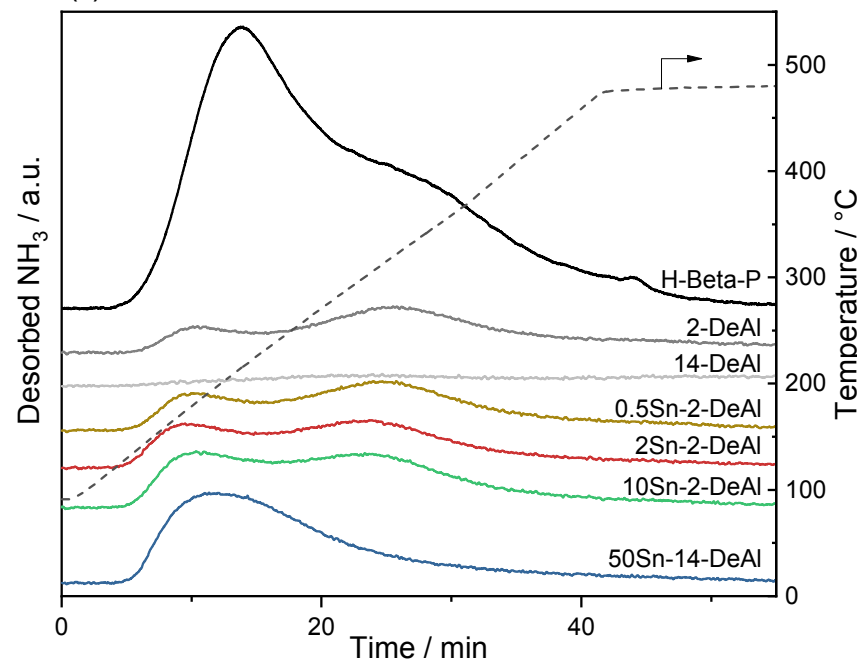

(b)

(b) $\quad-50^{\circ} \mathrm{C}-150^{\circ} \mathrm{C}-300^{\circ} \mathrm{C}$

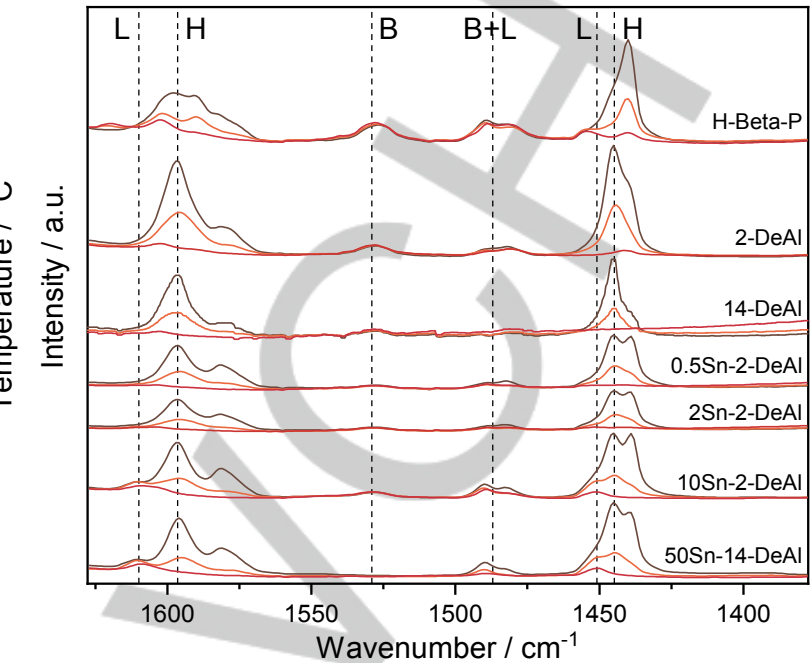

Fig. 3. Characterization of the acidity of the various catalysts by (a) $\mathrm{NH}_{3}-\mathrm{TPD}$ and (b) pyridine-FTIR spectroscopy at various temperature (H indicates $\mathrm{H}$-bonded pyridine, while $L$ and $B$ respectively indicate pyridine bonded to Lewis and Brønsted sites).

Sn concentration in $0.5 \mathrm{Sn}-2 \mathrm{DeAl}$ was too low to acquire an effective signal and is thus not displayed. However, due to the similarity in the grafting method, we suggest that Sn coordination to the framework is similar to the other dealuminated samples. Overall, these characterization results indicate that Sn grafting resulted in the incorporation of $\mathrm{Sn}$ in a tetrahedral coordination within the dealuminated BEA framework.

Samples acidity was quantified by $\mathrm{NH}_{3}$-TPD (Fig. 3a, Table 1). Overall, partial dealumination reduced the acid sites concentration from 0.880 to $0.196 \mathrm{mmol} \cdot \mathrm{g}^{-1}$ for $\mathrm{H}$-Beta-P and 2DeAl, respectively. 14-DeAl contained a residual acidity of $0.081 \cdot \mathrm{mmol} \mathrm{g}^{-1}$. Meanwhile, the acidity of the partially dealuminated, Sn-modified samples increased proportionally to the Sn loading. Sn grafting on 14-DeAl resulted in the appearance of a peak centered around $200{ }^{\circ} \mathrm{C}$ in its $\mathrm{NH}_{3}$-TPD profile and increased its acidity to $0.230 \mathrm{mmol} \cdot \mathrm{g}^{-1}$, close to the acidity of 10Sn-2-DeAl $\left(0.225 \mathrm{mmol} \cdot \mathrm{g}^{-1}\right)$. The nature and strength of the catalysts acid sites were studied by infrared spectroscopy of adsorbed pyridine (Fig. 3b). Characteristic vibrational bands of $\mathrm{H}$ bonded pyridine (1444 and $1596 \mathrm{~cm}^{-1}$ ), and pyridine bonded to a Brønsted $\left(1530 \mathrm{~cm}^{-1}\right)$ or a Lewis site $\left(1451\right.$ and $\left.1610 \mathrm{~cm}^{-1}\right)$ were detected. ${ }^{[38]}$ Comparison of H-Beta-P and 2-DeAl spectra shows that dealumination did not affect the strength of Brønsted acid sites as the signal intensity remained constant with increasing temperatures. Notably, all dealuminated samples displayed a higher signal due to $\mathrm{H}$-bonded pyridine to silanol groups. $0.5 \mathrm{Sn}$ 2-DeAl, 2Sn-2-DeAl and 10Sn-2-DeAl all displayed Brønsted and Lewis acidity while $50 \mathrm{Sn}-14-\mathrm{DeAl}$ only exhibited Lewis acidity. Signals corresponding to Lewis acid sites were more clearly observed for 50Sn-14-DeAl and 10Sn-2-DeAl due to the higher $\mathrm{Sn}$ content. The signals assigned to Lewis sites of Sn-modified samples slightly decreased with increasing temperatures and thus correspond to a moderate acid strength. Overall, H-Beta-P and 2-DeAl contained strong Brønsted sites, 50Sn-14DeAl possessed moderate Lewis acidity, and the partially dealuminated, Sn-modified samples contained strong Brønsted and moderate Lewis acidity. The latter is thus provided from tetrahedral Sn incorporated in the dealuminated framework.

\section{Catalytic performance screening for various OME synthesis reactions}

In order to elucidate the role of Lewis and Brønsted acid sites during the various steps of OME synthesis, the synthesized catalysts were used for the reactions described in Scheme 3: $\mathrm{OME}_{1}$ and TRI (R1), OME 1 and $\mathrm{PF}(\mathrm{R} 2), \mathrm{FA}$ and $\mathrm{MeOH}(\mathrm{R} 3)$ and $\mathrm{OME}_{2}$ equilibration (R4).

Scheme 3. Various reactions performed for the synthesis of OME. The different sources of formaldehyde are displayed in red.

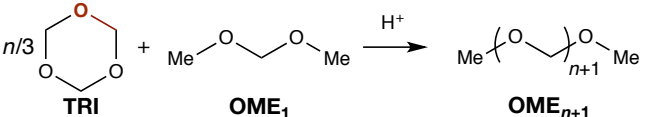

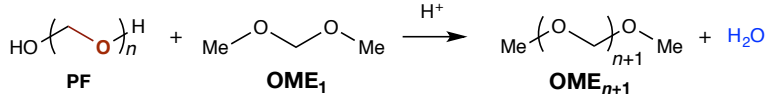

$$
\begin{aligned}
& n=\mathrm{O}+2 \mathrm{Me}-\mathrm{OH} \stackrel{\mathrm{H}^{+}}{\longrightarrow} \mathrm{Me} \mathrm{f}^{\mathrm{O}} \mathrm{Hn}_{\mathrm{N}}^{\mathrm{O}}-\mathrm{Me}+\mathrm{H}_{2} \mathrm{O} \\
& \text { FA } \mathrm{MeOH} \mathrm{OME}_{n} \\
& m_{\mathrm{Me}}-\mathrm{O}^{\mathrm{O}} \sim^{\mathrm{O}}{ }_{\mathrm{Me}} \stackrel{\mathrm{H}^{+}}{\longrightarrow} m_{\mathrm{Me}} \mathrm{f}^{\mathrm{O}} \sim_{n} \mathrm{O}_{\mathrm{Me}} \\
& \mathrm{OME}_{2} \quad \mathrm{OME}_{n}
\end{aligned}
$$


First, TRI and $\mathrm{OME}_{1}$ (R1) were used as reactants (Fig. 4a). A decrease in activity was observed with an increase in dealumination extent. Addition of Lewis acid sites on the completely dealuminated zeolite did not increase the sample activity as 14-DeAl and $50 \mathrm{Sn}-14-\mathrm{DeAl}$ had similar minor TRI conversion and formaldehyde concentration. Compared to 2-DeAl, catalysts displaying both Brønsted and Lewis sites had a much higher activity, comparable to H-Beta-P, despite their much lower concentration of acid sites.

The synthesis of OME using PF and $\mathrm{OME}_{1}(\mathrm{R} 2)$ displayed results similar to R1 with a large increase in activity when both Lewis and Brønsted sites were present (Fig. 4b). However, two differences were noticed. First, dealumination had a more severe effect on the performance; 2-DeAl reached a $\mathrm{OME}_{2-8}$ concentration of only $0.70 \mathrm{~mol} \cdot \mathrm{L}^{-1}$, compared to $2.86 \mathrm{~mol} \cdot \mathrm{L}^{-1}$ for $\mathrm{H}$-Beta-P. Second, $50 \mathrm{Sn}-14-\mathrm{DeAl}$ had a notably better performance $\left(0.56 \mathrm{~mol} \cdot \mathrm{L}^{-1}\right)$ compared to 14-DeAl $\left(0.05 \mathrm{~mol} \cdot \mathrm{L}^{-1}\right)$, but still much lower compared to H-Beta-P. Lewis acid sites were thus active in R2, but less than Brønsted acid sites, as more OME were produced using 2-DeAl than 50Sn-14-DeAl, despite the larger acid site concentration of the latter.

Next, the synthesis of OME from FA and $\mathrm{MeOH}$ (R3, Fig. 4c) was performed. The effect of dealumination on the performance was more severe on the catalyst performance compared to R1 and R2. After $16 \mathrm{~h}, 2-\mathrm{DeAl}$ and 14-DeAl respectively reached a OME2-8 concentration of 0.15 and $0.05 \mathrm{~mol} \cdot \mathrm{L}^{-1}$, compared to $3.01 \mathrm{~mol} \cdot \mathrm{L}^{-1}$ for H-Beta-P. Meanwhile, no clear increase in activity was observed when both Brønsted and Lewis sites were present; 0.5Sn-2-DeAl had performance comparable to 2-DeAl. However, Lewis acid sites also contributed to OME synthesis, as 2Sn-2DeAl, $10 \mathrm{Sn}-2-\mathrm{DeAl}$ and $50 \mathrm{Sn}-14-\mathrm{DeAl}$ had an activity superior to the dealuminated samples. The presence of water, produced in large amounts from reaction R3, seemed to affect Lewis acid sites more severely than Brønsted acid sites, as the results after $48 \mathrm{~h}$ showed a higher relative increase for all samples containing Brønsted acid sites compared to $50 \mathrm{Sn}-14 \mathrm{DeAl}$ bearing only Lewis acid sites.

To gain a better insight into the role of Lewis acid sites, $\mathrm{OME}_{2}$ equilibration into a SF distribution of OME (R4) was performed. This reaction also requires OME activation on an acid site for FA units to be transferred between different OME. It occurs under anhydrous conditions, similarly to R1, but does not involve TRI decomposition. Therefore, a SF distribution of OME was obtained from $\mathrm{OME}_{2}$ when exposed to an acidic catalyst. Fig. S5 demonstrates this effect with H-Beta-P: OME of various chain length were obtained as $\mathrm{OME}_{2}$ concentration decreased to reach a SF distribution. The rates of $\mathrm{OME}_{2}$ equilibration over the different catalysts followed the trend: H-Beta-P $>2$-DeAl $>0.5 \mathrm{Sn}$ 2-DeAl > 14-DeAl > 50Sn-14-DeAl (Fig. 5). As Sn-modified catalysts have lower performance compared to their dealuminated counterparts, it is clear that Brønsted acidity is required to activate OME for the equilibration reaction $\mathrm{R} 4$, while Lewis acidity is insufficient for this purpose.

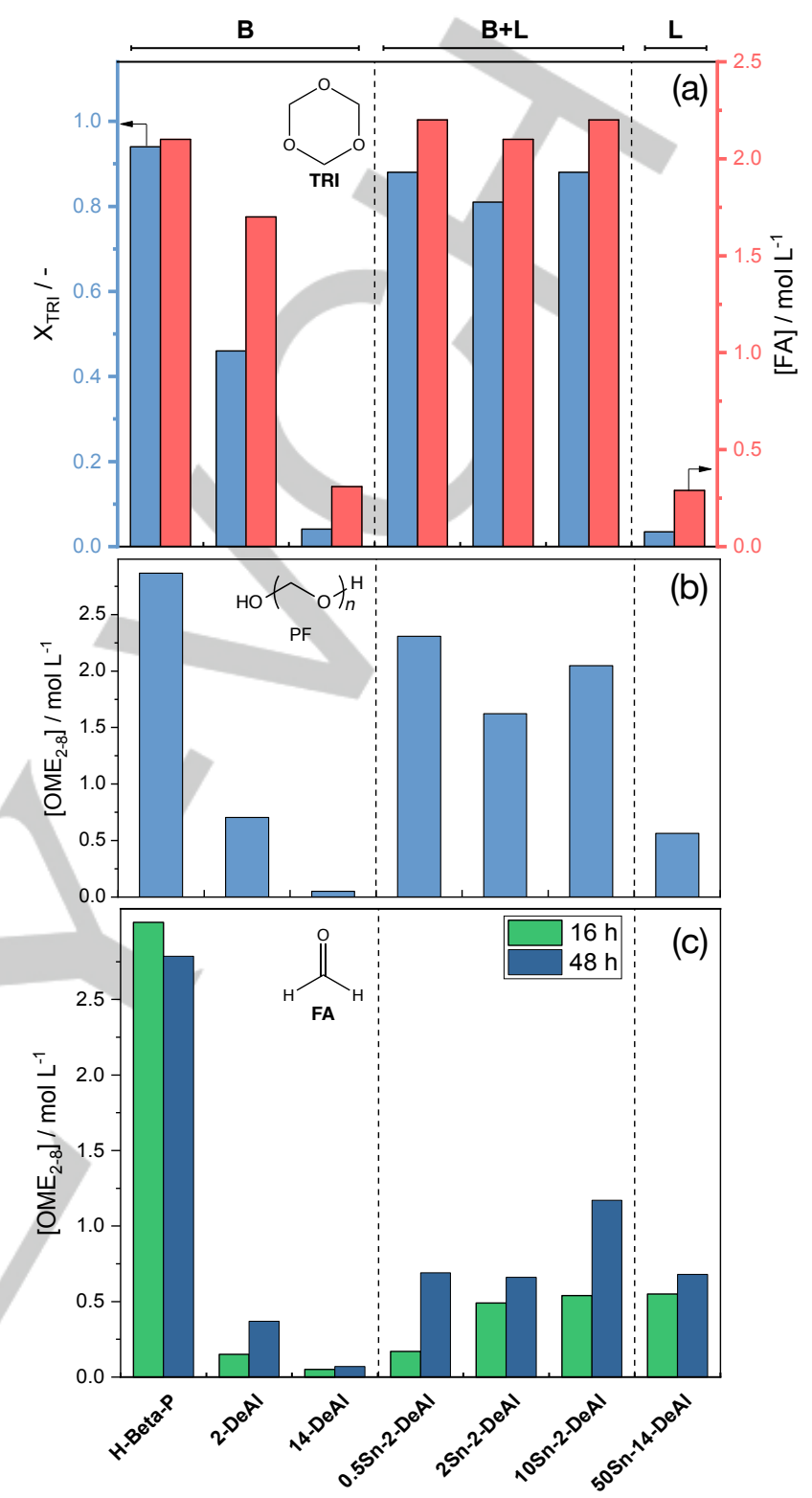

Fig. 4. Synthesis of OME using various catalysts: (a) TRI conversion $X_{T R I}$ and FA concentration using $\mathrm{OME}_{1}$ and $\mathrm{TRI}\left(\mathrm{T}=30^{\circ} \mathrm{C}, 0.5 \mathrm{wt}\right.$. \% catalyst, reaction time of $20 \mathrm{~min}$, molar ratio $\mathrm{OME}_{1}: \mathrm{TRI}=3.3$ ), (b) $\mathrm{OME}_{2-8}$ concentration using $\mathrm{OME}_{1}$ and $\mathrm{PF}\left(\mathrm{T}=60^{\circ} \mathrm{C}, 0.5 \mathrm{wt}\right.$. \% catalyst, reaction time of $20 \mathrm{~min}$, molar ratio $\left.\mathrm{OME}_{1}: \mathrm{FA}=1.1\right)$, and (c) $\mathrm{OME}_{2-8}$ concentration using $\mathrm{FA}$ and $\mathrm{MeOH}\left(\mathrm{T}=80^{\circ} \mathrm{C}\right.$, 1.0 wt. $\%$ catalyst, molar ratio $\mathrm{MeOH}: \mathrm{FA}=2.0$ ). 


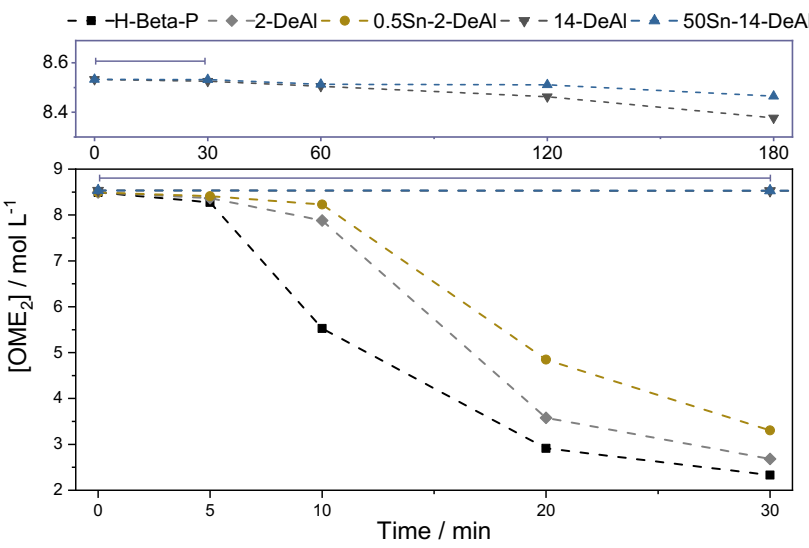

Fig. 5. Equilibration of $\mathrm{OME}_{2}(99.0 \%)$ into $\mathrm{OME}_{n}$ using various catalysts $(\mathrm{T}=$ $25^{\circ} \mathrm{C}, 1.0 \mathrm{wt}$. \% catalyst) (bottom). The reaction was performed at a larger timescale for 14-DeAl and 50Sn-14-DeAl (top).

TRI decomposition in DCM was performed using various catalysts in order to understand the interaction of grafted Sn with TRI in the absence of $\mathrm{OME}_{1}$ (Fig. 6). TRI decomposition increased with an increasing $\mathrm{Al}$ content: $\mathrm{H}-$ Beta-P reached a TRI conversion of 0.34 compared to 0.26 and 0.13 for 2-DeAl and 14-DeAl, respectively. Addition of $\mathrm{Sn}$ in the zeolite framework at low concentrations did not alter the conversion significantly: $0.5 \mathrm{Sn}-2-\mathrm{DeAl}$ and $2 \mathrm{Sn}-2-$ DeAl reached a TRI conversion of 0.26 and 0.24 , respectively. However, at higher Sn concentrations, TRI conversion increased by 31 and $29 \%$ for $50 \mathrm{Sn}-14 \mathrm{DeAl}$ and $10 \mathrm{Sn}-2 \mathrm{DeAl}$, respectively, compared to their dealuminated counterparts. Meanwhile, MF production augmented with increasing $\mathrm{Sn}$ content for partially dealuminated, Sn-containing zeolites. However, the combination of Brønsted and Lewis sites resulted in the highest MF production among Sn-containing zeolites. Notably, 50Sn-14-DeAl produced approximatively half the amount of MF compared to 10Sn-2-Deal despite the same total acidity and a three-fold Sn concentration in the zeolite. It thus appears that Brønsted acid sites were considerably more active for the TRI decomposition compared to Lewis acid sites. Presence of $\mathrm{Sn}$ resulted in the production of MF, especially when combined with Brønsted acid sites.

Overall, strong Brønsted acid sites resulting from bridging hydroxyl groups were active for all reactions performed. For catalysts containing only Brønsted acidity, an increasing extent of dealumination always led to a decrease in catalytic performance. In contrast, moderate Lewis acid sites resulting from tetrahedral Sn were inactive for R1 and R4, but still provided moderate activity for R2 and R3. When both Brønsted and Lewis acid sites were present, in combination with $\mathrm{OME}_{1}$ and a source of formaldehyde, a large increase in activity was observed which is ascribed to a synergistic effect between both acid sites.

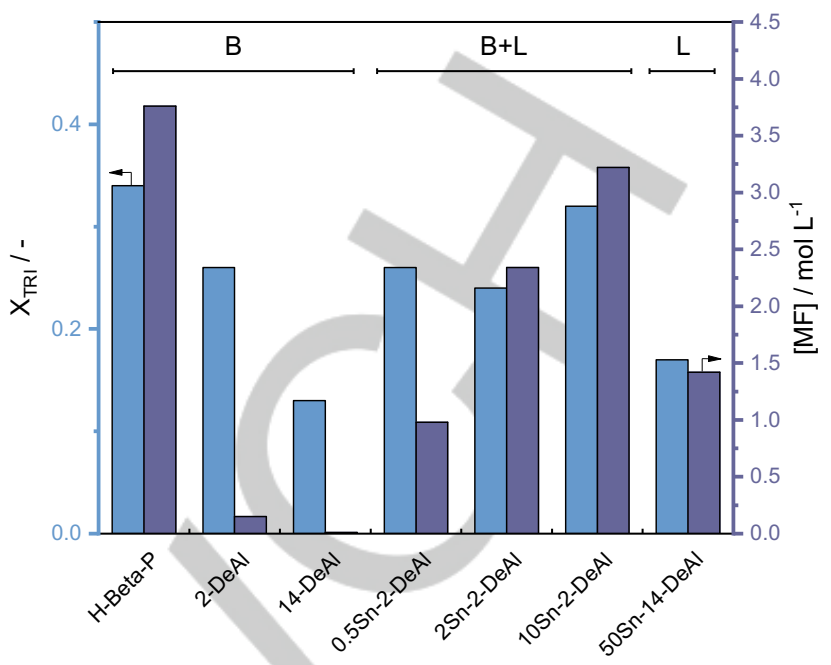

Fig. 6. TRI conversion $\mathrm{X}_{\mathrm{TRI}}$ and MF concentration for the TRI decomposition in DCM using various catalysts $\left(T=70{ }^{\circ} \mathrm{C}, 2.0 \mathrm{wt}\right.$. \% catalyst, reaction time of 64 h, $10 \%$ TRI in DCM).

Synergy between Brønsted and Lewis acid sites for OME synthesis from TRI and $\mathrm{OME}_{\mathbf{1}}$

In order to get a better insight into the nature of this synergistic effect, reaction R1 was performed with higher time resolution with $\mathrm{H}$-Beta-P, 2-DeAl and the partially dealuminated, Sn-modified samples (Fig. 7a). All catalysts exhibited a transition period in the beginning of the reaction due to an equilibration of temperature between the reactor and the thermostated bath. This resulted in an acceleration of the reaction rate observed for all catalysts during the first five minutes of the reaction. $\mathrm{H}$-Beta-P first reached the maximal TRI conversion, closely followed by the zeolites containing both Brønsted and Lewis acid sites. However, the turnover frequency (TOF) was the lowest over H-Beta-P, followed by 2-DeAl (Fig. 7a, inset). The higher TOF value obtained with 2DeAl compared to H-Beta-P could be due to a combination of two factors. First, dealuminated zeolites have stronger acid sites (higher $\mathrm{Si} / \mathrm{Al}$ ), which could accelerate the catalytic cycle due to reduced values of activation energy. ${ }^{[39]}$ Second, the dealumination treatment could have remove possible Al-rich debris present in the parent zeolite framework, thereby lowering the risk of OME internal molecular diffusion limitation. ${ }^{[13]}$

Compared to 2-DeAl and H-Beta-P, a two- and four-fold increase of the TOFs was observed obtained for 0.5Sn-2-DeAl, respectively, which we explain with the synergistic effect of Brønsted and Lewis acid sites. However, addition of Sn beyond the concentration in $0.5 \mathrm{Sn}-2 \mathrm{DeAl}$ resulted in a decrease of the TOFs. Such trend was already reported for the Sn-Beta in other catalytic reactions and means that not each $S n$ species is active for OME synthesis. ${ }^{[40,41]}$

MF is a by-product of OME synthesis and results from the condensation of two formaldehyde units. ${ }^{[2]} \mathrm{MF}$ production was notably higher for H-Beta-P, while partial dealumination suppressed MF production to values below the detection limit (Fig. $7 b)$. This phenomenon is probably due to the reduced acid site 
density and the resulting increased distance between two Brønsted sites in the zeolite framework obtained in 2-DeAl. ${ }^{[9]}$
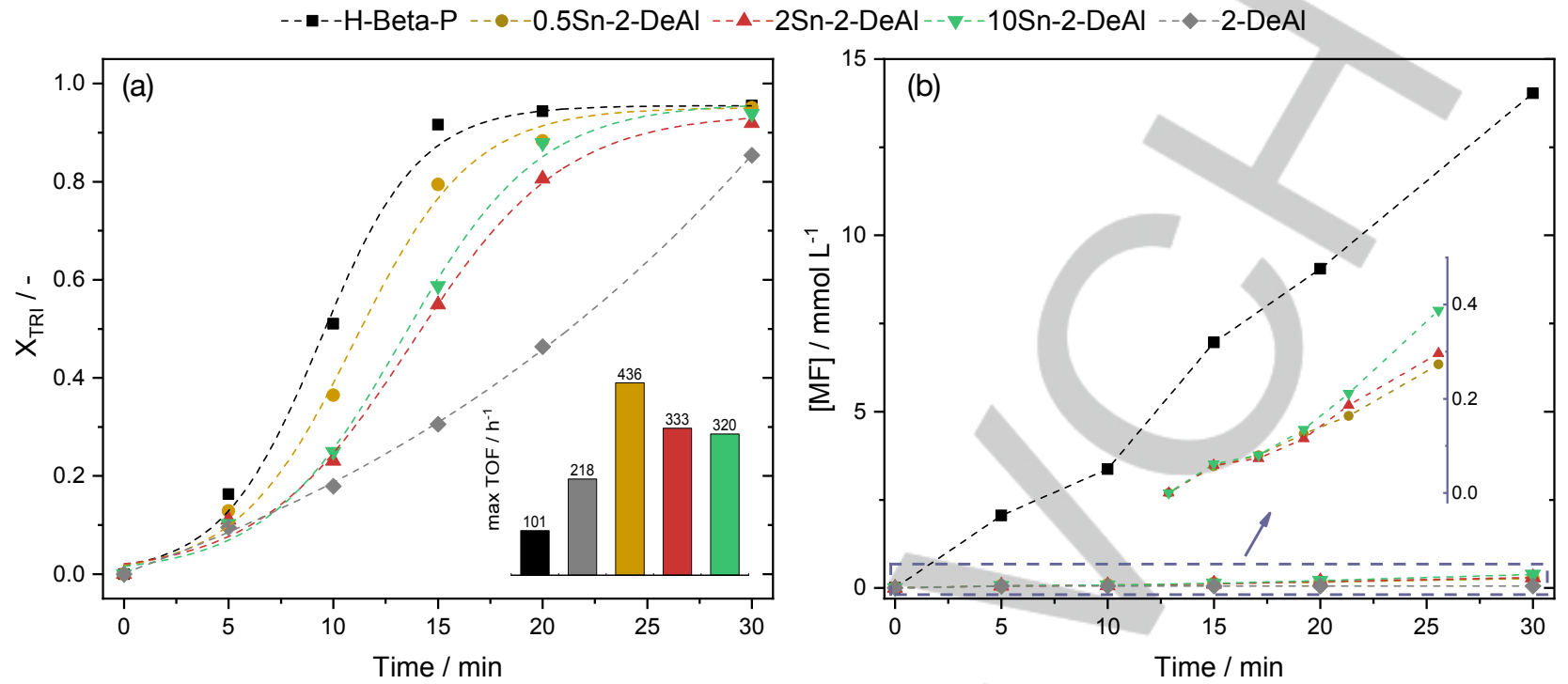

Fig. 7. Synthesis of $\mathrm{OME}$ using various catalysts from $\mathrm{OME}_{1}$ and $\mathrm{TRI}$ concentration $\left(\mathrm{T}=30^{\circ} \mathrm{C}, 0.5\right.$ wt. $\%$ catalyst, molar ratio $\mathrm{OME}$ : $\left.\mathrm{TRI}=3.3\right)$. (a) $\mathrm{TRI}$ conversion $X_{T R I}$ vs. time and (inset) max TOF. The experimental data were fitted using the Boltzmann model and the maximum rate of reaction is calculated in Fig. S6. (b) Methyl formate production vs. time.

When the average distance between two Brønsted sites exceeds the distance, which is required for condensation of two formaldehyde units, MF formation is no longer possible. Lewis acid sites were also producing MF, proportionally to the Sn loading (Fig. 7b, inset). However, their activity was much lower compared to Brønsted sites. After 30 minutes, 10Sn-2-DeAl produced $0.39 \mathrm{mmol} \cdot \mathrm{L}^{-1}$ of $\mathrm{MF}$ compared to $14.02 \mathrm{mmol} \cdot \mathrm{L}^{-1}$ for $\mathrm{H}$ Beta-P.

Analysis of other reaction parameters provided additional evidence on the nature of the synergistic effect. First, all samples displayed a linear relationship between the concentration of $\mathrm{OME}_{2-8}$ and TRI conversion (Fig. 8a) with only small amounts of the intermediate FA found in the reaction mixture. This suggests that TRI decomposition to formaldehyde was the rate determining step. This interpretation is in accordance with previous studies that have identified decomposition of the FA source as the rate limiting step and its large energy barrier (between $60-80 \mathrm{~kJ} \cdot \mathrm{mol}^{-}$ $\left.{ }^{1}\right) .{ }^{[19,21,25,42]}$ Additionally, FA concentration only increased during the reaction for all catalysts and reached a stable level once a SF distribution of OME was reached (Fig. S7a), suggesting that FA insertion is not the rate limiting step of the reaction.
Furthermore, it challenges the possibility that tetrahedral Sn assists with the decomposition of TRI into formaldehyde units. A higher TRI conversion for a specific concentration of product should have been observed if tetrahedral Sn had been active in TRI decomposition, and this effect should have increased with increasing Sn content, which was not observed. FA concentration as a function of TRI conversion was also independent of the various catalysts, which means that TRI conversion reflects the reaction progress (Fig. S7b).

This was further confirmed by the analysis of the intermediate-toproduct ratio (FA/OME $2-8$ ) as a function of TRI conversion (Fig. $8 b)$. Catalysts containing only Brønsted acid sites and catalysts containing both Lewis and Brønsted acid sites displayed a similar pattern, which suggests that FA concentration during the reaction was a function of the reaction progress and was not influenced by the presence of Lewis acid sites.

TRI insertion into $\mathrm{OME}_{1}$ to form $\mathrm{OME}_{4}$ was observed in the beginning of the reaction (Fig. S8). However, this phenomenon was not promoted by using dealuminated, Sn-containing zeolites. Therefore, the possibility that Lewis acid sites assist TRI insertion in $\mathrm{OME}_{1}$ was ruled out. 

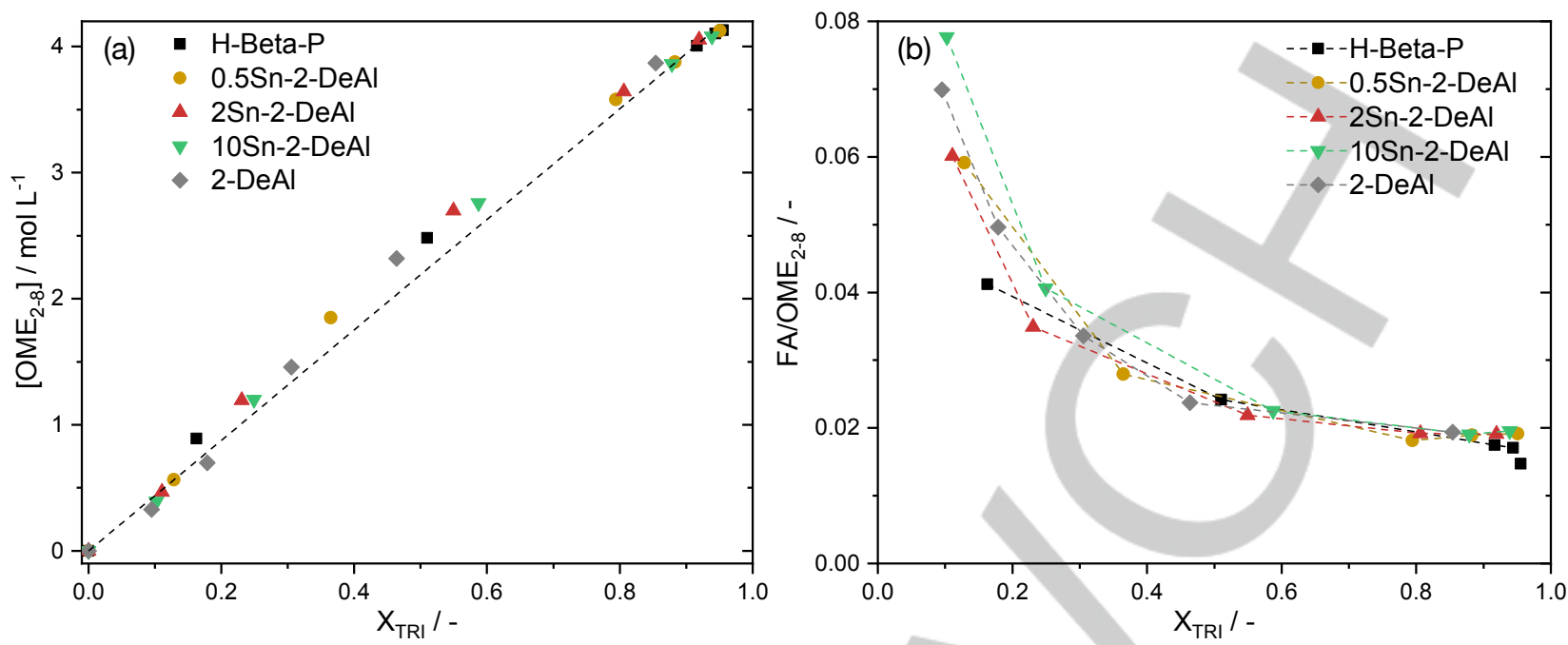

Fig. 8. Synthesis of $\mathrm{OME}$ using various catalysts from $\mathrm{OME}_{1}$ and $\mathrm{TRI}$ concentration $\left(\mathrm{T}=30{ }^{\circ} \mathrm{C}, 0.5\right.$ wt. $\%$ catalyst, molar ratio $\mathrm{OME}$ : $\mathrm{TRI}=3.3$; $(\mathrm{a}) \mathrm{OME} 2-8$ concentration vs. TRI conversion $\mathrm{X}_{\mathrm{TRI}}$ and (b) intermediate to product ratio vs. TRI conversion $\mathrm{X}_{\mathrm{TRI}}$.

\section{Discussion}

Catalyst characterization demonstrated that tetrahedrally coordinated Sn was successfully incorporated in the framework of the dealuminated zeolites. The partially dealuminated, Sn-grafted samples presented both Brønsted and Lewis acid sites, while $\mathrm{H}$ Beta-P and 2-DeAl exhibited Brønsted acid sites and 50Sn-14DeAl only Lewis acid sites. It has to be mentioned that H-Beta-P might contain residual Lewis acidity below the detection limit due to extra-framework Al. For 50Sn-14-DeAl, ICP-OES indicated residual aluminum, which is a potential source of Brønsted acidity. However, pyridine adsorption spectroscopy did not show any sign of Brønsted acidity for this sample and only Lewis acidity could be found. We conclude from these findings that the potential residual Lewis acidity in H-Beta-P and Brønsted acidity in 50Sn-14-DeAl can be neglected in the interpretation of the results. Please note that due to the low concentration of $\mathrm{Sn}$ in $0.5 \mathrm{Sn}-2-\mathrm{DeAl}$, some characterization methods such as MAS-NMR could not provide enough signal and the state of Sn was thus interpreted using samples with a larger $\mathrm{Sn}$ concentration.

These catalysts were used in a series of reactions to clarify the role of Lewis and Brønsted acid sites in the various synthesis steps (Table 2). Strong Brønsted acid sites, resulting from bridging hydroxyl groups, were active in all OME synthesis steps (i.e. initiation, growth and termination), independent of the reactants. Dealumination decreased the concentration of Brønsted acid sites, leading to an almost proportional reduction of the catalyst performance. In comparison, Lewis acid sites resulting from tetrahedrally coordinated $\mathrm{Sn}$ incorporated in the zeolite framework were not active in all steps involved in OME synthesis. First, Lewis acid sites could not catalyze the OME initiation/termination step. Second, they could not decompose TRI into FA units, while they could decompose PF. However, a synergy between Brønsted and Lewis acidity was observed for the reaction of $\mathrm{OME}_{1}$ with TRI or PF. Notably, production of OME from $\mathrm{OME}_{1}$ and TRI using $0.5 \mathrm{Sn}-14 \mathrm{DeAl}$ resulted in a four-fold increase in TOF compared to H-Beta. No synergy was detected when producing OME from $\mathrm{MeOH}$ and FA.

The first difference in activity between Lewis and Brønsted acid sites was observed during the initiation-termination step, which, unlike Brønsted acid sites, did not occur on Lewis acid sites. On the one hand, $\mathrm{OME}_{2}$ equilibration experiments demonstrated that addition of $\mathrm{Sn}$ was detrimental to the catalyst performance, showing the inability of Lewis acid sites to activate $\mathrm{OME}_{2}$ through generation of a carbocation. On the other hand, tetrahedral Sncatalyzed OME synthesis from $\mathrm{FA}$ and $\mathrm{MeOH}$ demonstrated the activity of the Sn sites for acetalization. The activity of $50 \mathrm{Sn}$ 14DeAl in R2 is probably due to the generation of water from the decomposition of PF, which should be sufficient to reverse acetalization.

The second difference in activity is related to TRI decomposition into FA units, which did not occur on tetrahedrally coordinated Sn. 50Sn-14-DeAl exhibited an activity superior to 14-DeAl for R2, while both catalysts were inactive for R1.

Table 2. Activity comparison of Brønsted and Lewis acid sites for the various OME synthesis steps.

\begin{tabular}{|c|c|c|c|}
\hline Synthesis Steps & $\begin{array}{l}\text { Reactant } \\
\text { /intermediate }\end{array}$ & $\begin{array}{l}\text { Brønsted } \\
\text { (bridging } \\
\text { hydroxyl) }\end{array}$ & $\begin{array}{l}\text { Lewis } \\
\text { (tetrahedral } \\
\text { Sn) }\end{array}$ \\
\hline \multirow{2}{*}{ Initiation/Termination } & Carbocations & Active & Inactive \\
\hline & Hemiformal & Active & Active \\
\hline $\begin{array}{l}\text { Growth/Sequential } \\
\text { addition }\end{array}$ & & Active & Active \\
\hline \multirow{2}{*}{$\begin{array}{l}\text { Decomposition of FA } \\
\text { source }\end{array}$} & TRI & Active & Inactive \\
\hline & $\mathrm{PF}$ & Active & Active \\
\hline
\end{tabular}


Thus, PF must have been decomposed on Lewis acid sites into FA units, which were subsequently used for OME growth. However, it appeared that the activity of tetrahedrally coordinated Sn for PF decomposition was not as high as Brønsted acid sites. Meanwhile, TRI decomposition in DCM revealed that TRI conversion was due to the presence of Brønsted acid sites and that addition of low to moderate $\mathrm{Sn}$ concentration did not improve TRI conversion. Additionally, detailed investigation into R1 revealed that, despite their very different activity, the intermediate-to-product ratio did not vary during the course of the reaction among the catalysts (i.e. H-Beta-P, 2-DeAl, and partially dealuminated, Sn-modified samples). The possibility that TRI was inserted into $\mathrm{OME}_{1}$ was also discarded based on the comparison of $\mathrm{OME}_{4}$ production versus $\mathrm{OME}_{2-8}$.

The synergy between Brønsted and Lewis acidity, which resulted in a four-fold increase in TOF, was only observed for reactions involving $\mathrm{OME}_{1}$ and a FA source (i.e. R1 and R2). No synergy was detected when OME were produced from $\mathrm{MeOH}$ and FA. This is in accordance with the results of $\mathrm{Li}$ et al., showing no synergy between Brønsted and Lewis acid sites for the reaction of $\mathrm{MeOH}$ with TRI. ${ }^{[22]}$ It is important to note, from our results and previous studies, that such a synergy was only reported when $\mathrm{OME}_{1}$ was used as one of the reactants. ${ }^{[22,26]}$ The presence of water could also be an important factor to obtain such a synergy. When using $\mathrm{MeOH}$ or formalin, water from the reaction medium or produced during acetalization could coordinate with Lewis acid sites to convert them to Brønsted acid sites. That could potentially explain why no synergy was observed under these conditions. The effect of water on the reaction kinetics of OME synthesis from TRI and $O M E_{1}$ is currently investigated and subject of a separate study.

Because tetrahedral Sn was not active for TRI decomposition and OME initiation to carbocations, the synergy between Brønsted and Lewis acid sites can only be explained by a higher activity of tetrahedral $\mathrm{Sn}$ in the OME growth step. FA units were made available by TRI decomposition on Brønsted acid sites and growth occurred on tetrahedral $\mathrm{Sn}$ as Lewis acid sites, which increased the overall reaction rate. Increasing the Sn concentration further in the partially dealuminated zeolite decreased the TOF, but presence of a small amount of Lewis acid sites may have been sufficient to rapidly incorporate the produced FA into OME.

Activation of the carbonyl group of FA by interaction with tetrahedral Sn could likely be the initial step for insertion of FA into OME. This finding was supported by results from TRI decomposition in DCM, which showed an increase in MF production with an increasing Sn content, which probably is a result of FA activation by Sn. Furthermore, dealuminated, Snmodified catalysts also produced much less MF compared to $\mathrm{H}$ Beta-P during OME synthesis, which suggests that FA units were rapidly inserted in OME. Thus, we suggest that the synergy between Brønsted and Lewis acid sites is a consequence of TRI dissociation on Brønsted acid sites and sequential addition on Lewis acid sites, as illustrated in Scheme 4.

\section{Conclusions}

In summary, tetrahedrally coordinated $\mathrm{Sn}$ was successfully incorporated in the framework of dealuminated BEA zeolites via Sn grafting in dichloromethane leading to a series of BEA zeolites with varying Lewis and Brønsted acid sites. The synthesized catalysts were used for a combination of OME synthesis reactions to clarify the role of Brønsted and Lewis acid sites. Our results demonstrated that Lewis acid sites resulting from tetrahedrally coordinated Sn were not active in all OME synthesis steps, while Brønsted acid sites were. Notably, TRI dissociation and $\mathrm{OME}_{1}$ activation did not occur on Lewis acid sites. The presence of both sites resulted in a synergy when $\mathrm{OME}_{1}$ was used with $\mathrm{PF}$ or TRI. Notably, 0.5Sn-2-Deal exhibited a significant increase in TOF and reduction in byproduct generation. This synergistic effect was explained by a more efficient FA insertion into OME on Lewis acid sites, while production of FA units by TRI or PF decomposition occurred on Brønsted acid sites. The interaction between tetrahedral $\mathrm{Sn}$ and the carbonyl group of FA resulted in an activated FA, likely to be inserted into OME.

Scheme 4. Suggested reaction mechanism for the synthesis of OME from OME 1 and TRI with Brønsted and Lewis sites. Reaction with $\mathrm{OME}_{1}$ was depicted for readability. 


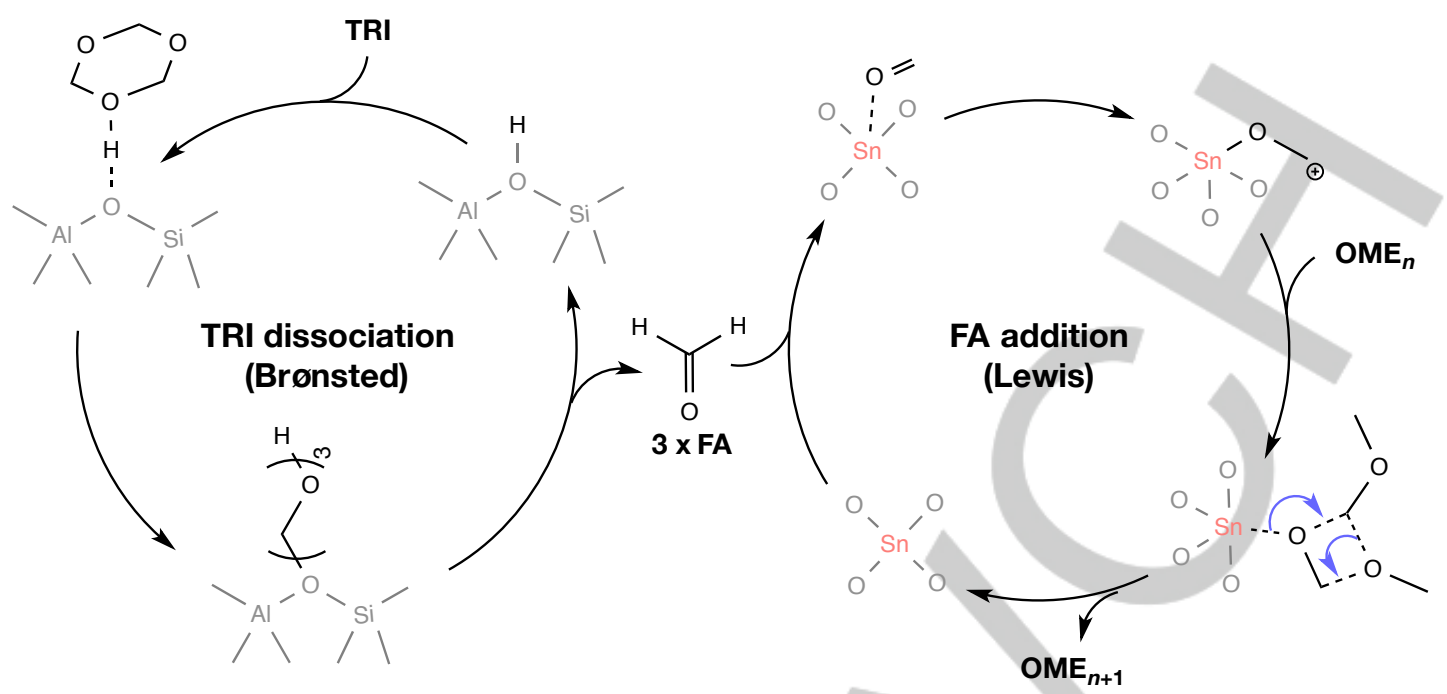

\section{Experimental Section}

\section{Partial and complete dealumination of zeolite Beta}

Partial or complete dealumination were performed on a Beta zeolite (Si/AI $=11, \mathrm{ABCR})$. The parent $\mathrm{H}$-Beta zeolite $(\mathrm{H}$-Beta- $\mathrm{P})$ was first obtained by calcination of $\mathrm{NH}_{4}$-Beta at $550{ }^{\circ} \mathrm{C}$ for $5 \mathrm{~h}$ with a $10^{\circ} \mathrm{C} \cdot \mathrm{min}^{-1}$ temperature ramp. Partial dealumination was achieved by stirring the zeolite overnight in a $2.0 \mathrm{M}$ solution of nitric acid $\left(\mathrm{HNO}_{3}, 65 \%\right.$, Sigma Aldrich) at $80{ }^{\circ} \mathrm{C}$ under reflux (55 mL $\cdot \mathrm{g}^{-1}$ catalyst). Alternatively, a solution of $14.0 \mathrm{M} \mathrm{HNO}_{3}$ (50 mL $\cdot \mathrm{g}^{-1}$ catalyst) stirred at $100{ }^{\circ} \mathrm{C}$ under reflux for $8 \mathrm{~h}$ was used for complete dealumination. The partially or completely dealuminated zeolite was then filtered and repeatedly washed with deionized water until a neutral $\mathrm{pH}$ was reached. The powder was then dried overnight in an oven at $110^{\circ} \mathrm{C}$. The partially and completely dealuminated zeolites were named 2-DeAl and 14-DeAl, respectively, according to the $\mathrm{HNO}_{3}$ concentration used during the treatment.

\section{Post-synthetic Sn grafting of dealuminated Beta zeolite in} dichloromethane

Dealuminated Beta zeolite (2-DeAl or 14-DeAl) was first thoroughly dried under vacuum at $200{ }^{\circ} \mathrm{C}$ overnight. Anhydrous dichloromethane (DCM, $99.8 \%$, Acros) was added to the powder through moisture-free cannula transfer $\left(100 \mathrm{~mL} \cdot \mathrm{g}^{-1}\right.$ catalyst) using Schlenk technique. A determined amount of $\mathrm{SnCl}_{4}(1.0 \mathrm{M}$ in DCM, Acros) was subsequently added with a syringe and the mixture was stirred magnetically $(450 \mathrm{rpm})$ at $70{ }^{\circ} \mathrm{C}$ for 7 $h$ under reflux in $\mathrm{N}_{2} .{ }^{[27]}$ The powder was then recovered by filtration and thoroughly washed with dry isopropanol (Acros). Next, the recovered solid was dried at $110^{\circ} \mathrm{C}$ overnight and calcined at $550{ }^{\circ} \mathrm{C}$ for $5 \mathrm{~h}$ under static air with a temperature ramp of $10^{\circ} \mathrm{C} \cdot \mathrm{min}^{-1}$. Each catalyst is denoted as $x S n-y-D e A l$, where $x$ and $y$ are the $S n$ precursor concentration and the $\mathrm{HNO}_{3}$ concentration during dealumination, respectively.

\section{Material Characterization}

$\mathrm{N}_{2}$ physisorption experiments were performed on a Micrometrics 3Flex apparatus at $77 \mathrm{~K}$ and $\mathrm{N}_{2}$ relative pressures between $10^{-5}$ and 0.99 . Typically, samples (ca. $150 \mathrm{mg}$ ) were dried at $120{ }^{\circ} \mathrm{C}$ (temperature ramp $5{ }^{\circ} \mathrm{C} \cdot \mathrm{min}^{-1}$ ) for $5 \mathrm{~h}$. A leak test was performed before the analysis. Brunauer-Emmett-Teller (BET) surface, Barrett-Joyner-Helenda (BJH) and t-plot method were used, respectively, to calculate the specific surface area, the mesoporous, and microporous volume. Elemental analyses were performed using inductively coupled plasma optical emission spectrometry (ICP-OES) at the Paul Scherrer Institute on a Vista pro AX Varian instrument. A $10 \mathrm{~mL}$ aqueous solution containing $0.5 \mathrm{~mL}$ of $65 \%$ nitric acid, $0.5 \mathrm{~mL}$ of $40 \%$ hydrofluoric acid and $0.25 \mathrm{~mL}$ of $30 \%$ hydrochloric acid was used for the digestion of $50 \mathrm{mg}$ of catalyst at $95^{\circ} \mathrm{C}$ for $2 \mathrm{~h}$.

XPS spectra were recorded using a monochromatic Al Ka X-ray source of 24.8 W and a beam size of $100 \mu \mathrm{m}$ on a PHI VersaProbe II scanning XPS microprobe (Physical Instruments AG, Germany). X-ray diffraction (XRD) patterns were recorded using a D8 advance Bruker instrument equipped with a 1D-LynxEye detector (Cu K $\alpha$ radiation, no monochromator, Ni filter) at a step size of $0.01^{\circ}$. The structure of the samples was studied by highangle annular dark-field scanning transmission electron micros- copy (HAADF-STEM) on a FEI Tecnai Osiris with $200 \mathrm{kV}$ acceleration voltage. The energy-dispersive X-ray spectroscopy results were analyzed using Bruker Esprit Software. Grids were prepared by deposition of a drop of ethanol containing the sample on a Lacey carbon grid.

Magic angle spinning nuclear magnetic resonance (MAS-NMR) was used to investigate the coordination and chemical environment of Sn. ${ }^{119} \mathrm{Sn}$ single-pulse spectra were collected on a $500 \mathrm{MHz}$ Bruker instrument equipped with a $11.7 \mathrm{~T}$ magnet, at room temperature with a $35 \mathrm{kHz}$ spinning rate. The Carr-Purcell-Meiboom-Gill (CPMG) pulse sequence was performed to increase the sensitivity, on a $900 \mathrm{MHz}$ Bruker Advance instrument.

Concentration of acid sites was calculated from temperature programmed desorption of $\mathrm{NH}_{3}\left(\mathrm{NH}_{3}\right.$-TPD) on a Micromeritics Autochem 2920 II instrument. Typically, the sample (ca. $100 \mathrm{mg}$ ) was loaded in a quartz cell and dried with a He flow $\left(50 \mathrm{~mL} \cdot \mathrm{min}^{-1}\right)$ at $200{ }^{\circ} \mathrm{C}\left(2{ }^{\circ} \mathrm{C} \cdot \mathrm{min}^{-1}\right.$; hold time of 120 min). Saturation of the sample with $\mathrm{NH}_{3}$ was done using a volumetric ratio of 1:99 for $\mathrm{NH}_{3}$ and $\mathrm{He}$ during $1 \mathrm{~h}$ at $50{ }^{\circ} \mathrm{C}$. Physisorbed $\mathrm{NH}_{3}$ was then removed with $\mathrm{He}\left(50 \mathrm{~mL} \cdot \mathrm{min}^{-1}\right)$. The temperature was then increased to $600{ }^{\circ} \mathrm{C}\left(10^{\circ} \mathrm{C} \cdot \mathrm{min}^{-1}\right)$ and $\mathrm{NH}_{3}$ was monitored using a calibrated MKS Cirrus II mass spectrometer.

Diffuse reflectance infrared Fourier transform spectroscopy (DRIFTS) was performed by means of a high temperature Harrick DRIFT cell mounted on a Perkin Elmer Frontier spectrometer equipped with a mercury cadmium telluride detector. Spectra were recorded with 32 scans at a resolution of $4 \mathrm{~cm}^{-1}$ after being dried $2 \mathrm{~h}$ at $200^{\circ} \mathrm{C}$ under a $20 \mathrm{~mL} \cdot \mathrm{min}^{-1} \mathrm{He}$ flow. Pyridine adsorption experiments were done using the following procedure. First, the 
sample was dried and consequently saturated at $50{ }^{\circ} \mathrm{C}$ for 30 min under a He flow of $20 \mathrm{~mL} \cdot \mathrm{min}^{-1}$ bubbling through pyridine at room temperature. Physisorbed pyridine was then removed by flowing pure $\mathrm{He}\left(20 \mathrm{~mL} \cdot \mathrm{min}^{-1}\right)$ for $30 \mathrm{~min}$. Finally, the temperature was raised to 150 and $300{ }^{\circ} \mathrm{C}$ with a ramp rate of $5^{\circ} \mathrm{C} \mathrm{min}^{-1}$. Diffuse reflectance UV-Vis spectroscopy (DRUVS) spectra were recorded on a Varian spectrometer equipped with an in-situ Harrick Praying Mantis cell. In-situ measurements were done under a $\mathrm{N}_{2}$ flow of ca. $20 \mathrm{~mL} \cdot \mathrm{min}^{-1}$.

\section{Catalytic testing for OME synthesis}

TRI (99 \%) and PF were purchased from Sigma-Aldrich. OME 1 (99.5 \%) was obtained from Acros and $\mathrm{OME}_{2}$ to $\mathrm{OME}_{6}(99.0 \%)$ were purchased from ASG Analytics. The $\mathrm{H}_{2} \mathrm{O}$ content of $\mathrm{OME}_{1}$ was determined by KarlFisher titration $\left(0.04\right.$ wt. $\left.\% \mathrm{H}_{2} \mathrm{O}\right)$. A methanolic formaldehyde solution was prepared from $\mathrm{PF}$ and $\mathrm{MeOH}$. PF was dissolved in $\mathrm{MeOH}$ and heated overnight at $60{ }^{\circ} \mathrm{C}$ under magnetic stirring with the addition of a few drops of base (sodium methoxide). Undissolved PF was removed by filtration.

Synthesis of OME was performed in $10 \mathrm{~mL}$ pressure resistant glass reactors (Grace $\mathrm{GmbH}$ ). Typically, the reactors were loaded with catalysts and dried overnight at $110^{\circ} \mathrm{C}$. After cooling down to $\mathrm{RT}$, the reactants were added and the reactors were subsequently dipped in a water bath thermostated at the reaction temperature, which was considered as the start of the reaction. The reaction mixtures were stirred magnetically at 400 rpm and were quenched in ice at a determined time. Samples were filtered before analysis and formaldehyde titration. TRI decomposition in dichloromethane (DCM) was performed using a similar method, using a 10 wt. \% TRI solution of DCM, previously dried over molecular sieve. Reactors were loaded with 2 wt. \% catalyst, relative to TRI.

Analysis of the samples was performed on an Agilent 7890B/5977A series gas chromatograph-mass spectrometer (GC-MS) with an automated liquid sampler and an HP-5 capillary column (length $30 \mathrm{~m}$, outer diameter 0.32 $\mathrm{mm}$, film $1.05 \mu \mathrm{m})$. Quantification of $\mathrm{OME}_{1-6}$, methanol and methyl formate was done by means of a calibration curve that was obtained with pure reference materials. Calibration curves for $\mathrm{OME}_{7-8}$ were constructed based on the effective carbon number method and extrapolated from the response factors of $\mathrm{OME}_{1-6 .}{ }^{[43]}$ Formaldehyde concentration was determined by 3 successive titrations using the sodium sulfite method.

Experimental data from R1 were fitted with the Boltzmann function using the ORIGIN software. The turnover frequencies (TOFs) were calculated using the following formula:

$$
T O F_{\max }=\frac{\text { rate }_{\max }}{C_{a c} \cdot C_{c a t}}
$$

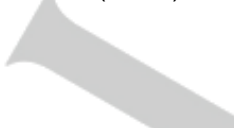

where rate $\max$ is the maximum value of the derivative of [OME $2-8]$ vs. time $\left(\mathrm{mol} \cdot \mathrm{L}^{-1} \cdot \mathrm{s}^{-1}\right), \mathrm{Cac}$ is the acid sites concentration of the catalyst $\left(\mathrm{mol} \cdot \mathrm{g}^{-1}\right)$ and $\mathrm{C}_{\text {cat }}$ is the catalyst concentration $\left(\mathrm{g} \cdot \mathrm{L}^{-1}\right)$.

\section{Acknowledgements}

This research project is financially supported by the Swiss Innovation Agency Innosuisse and is part of the Swiss Competence Center for Energy Research SCCER BIOSWEET. The authors are thankful to Dr. Davide Ferri and Prof. Jeremy Luterbacher for providing access to characterization equipment. The authors are grateful to Thibault Fovanna, Martin Elsener,
Snaedis Bjoergvinsdottir, Emilie Baudat and Pascal Schouwink for helping to characterize the catalysts.

Keywords: acidity $\cdot$ green chemistry $\cdot$ polyoxymethylene dimethyl ethers $\cdot$ tin $\cdot$ zeolite

[1] World Energy Council, Global Transport Scenarios 2050, 2011.

[2] J. Burger, M. Siegert, E. Ströfer, H. Hasse, Fuel 2010, 89, 33153319.

[3] B. Lumpp, D. Rothen, C. Pastötter, R. Lämmermann, E. Jacob, MTZ 2011, 72, 34-39.

[4] M. Härtl, K. Gaukel, D. Pélerin, G. Wachtmeister, MTZ Worldw. 2017, 2, 52-58

[5] S. E. Iannuzzi, C. Barro, K. Boulouchos, J. Burger, Fuel 2016, 167, 49-59.

[6] A. Feiling, M. Münz, C. Beidl, MTZ 2016, 16-21.

[7] W. Maus, E. Jacob, M. Härtl, P. Seidenspinner, G. Wachtmeister, in Internat. Wiener Mot., Düsseldorf, 2014, pp. 325-347.

[8] W. Maus, E. Jacob, R. Brück, P. Hirth, MTZ 2012, 73, 4-11.

[9] J. Burger, E. Ströfer, H. Hasse, Ind. Eng. Chem. Res. 2012, 51, 12751-12761.

[10] N. Schmitz, F. Homberg, J. Berje, J. Burger, H. Hasse, Ind. Eng. Chem. Res. 2015, 54, 6409-6417.

[11] Q. Zhao, H. Wang, Z. Qin, Z. Wu, J. Wu, W. Fan, J. Wang, J. Fuel Chem. Technol. 2011, 39, 918-923.

[12] J. Wu, H. Zhu, Z. Wu, Z. Qin, L. Yan, B. Du, W. Fan, J. Wang, Green Chem. 2015, 17, 2353-2357.

[13] C. J. Baranowski, A. M. Bahmanpour, F. Héroguel, J. S. Luterbacher, O. Kröcher, Catal. Sci. Technol. 2019, 9, 366-376.

[14] W. H. Fu, X. M. Liang, H. Zhang, Y. M. Wang, M. Y. He, Chem. Commun. 2015, 51, 1449-1452.

[15] C. J. Baranowski, A. M. Bahmanpour, F. E. Héroguel, J. Luterbacher, O. Kröcher, ChemCatChem 2019, 1-13.

[16] C. J. Baranowski, A. M. Bahmanpour, O. Kröcher, Appl. Catal. B Environ. 2017, 407-420.

[17] L. Lautenschütz, D. Oestreich, P. Haltenort, U. Arnold, E. Dinjus, J. Sauer, Fuel Process. Technol. 2017, 165, 27-33.

[18] D. Oestreich, L. Lautenschütz, U. Arnold, J. Sauer, Chem. Eng. Sci. 2017, 163, 92-104

[19] F. Wang, G. Zhu, Z. Li, F. Zhao, C. Xia, J. Chen, J. Mol. Catal. A Chem. 2015, 408, 228-236.

[20] N. Schmitz, J. Burger, H. Hasse, Ind. Eng. Chem. Res. 2015, 54, 12553-12560.

[21] T. J. Goncalves, U. Arnold, P. N. Plessow, F. Studt, ACS Catal. 2017, 7, 3615-3621.

[22] H. Li, H. Song, L. Chen, C. Xia, Appl. Catal. B Environ. 2015, 165, 466-476.

[23] Y. Zheng, Q. Tang, T. Wang, Y. Liao, J. Wang, Chem. Eng. Technol. 2013, 36, 1951-1956.

[24] Z. Xue, H. Shang, Z. Zhang, C. Xiong, C. Lu, G. An, Energy \& Fuels 2016, 31, 279-286

[25] J. Qi, Y. Hu, S. Jiang, W. Ma, Z. Yang, Y. Wang, Fuel 2019, 245, 521-527.

[26] F. Liu, T. Wang, Y. Zheng, J. Wang, J. Catal. 2017, 355, 17-25. 
J. C. Vega-Vila, J. W. Harris, R. Gounder, J. Catal. 2016, 344, 108120.

[28] J. Wang, Y. Masui, M. Onaka, ACS Catal. 2011, 1, 446-454.

[29] Y. Masui, J. Wang, K. Teramura, T. Kogure, T. Tanaka, M. Onaka, Microporous Mesoporous Mater. 2014, 198, 129-138.

[30] T. Hara, M. Hatakeyama, A. Kim, N. Ichikuni, S. Shimazu, Green Chem. 2012, 14, 771-777.

[31] V. K. Soni, P. R. Sharma, G. Choudhary, S. Pandey, R. K. Sharma, ACS Sustain. Chem. Eng. 2017, 5, 5351-5359.

[32] P. J. Wallis, W. P. Gates, A. F. Patti, J. L. Scott, E. Teoh, Green Chem. 2007, 9, 980.

[33] S. Bordiga, C. Lamberti, F. Bonino, A. Travert, F. Thibault-Starzyk, Chem. Soc. Rev. 2015, 44, 7262-7341.

[34] W. Dai, C. Wang, B. Tang, G. Wu, N. Guan, Z. Xie, M. Hunger, L. Li, ACS Catal. 2016, 6, 2955-2964.

[35] P. Ferrini, J. Dijkmans, R. De Clercq, S. Van de Vyver, M. Dusselier, P. A. Jacobs, B. F. Sels, Coord. Chem. Rev. 2017, 343, 220-255.

[36] J. A. Jennings, S. Parkin, E. Munson, S. P. Delaney, J. L. Calahan, M. Isaacs, K. Hong, M. Crocker, RSC Adv. 2017, 7, 25987-25997.

[37] P. Wolf, M. Valla, F. Núñez-Zarur, A. Comas-Vives, A. J. Rossini, C. Firth, H. Kallas, A. Lesage, L. Emsley, C. Copéret, et al., ACS Catal. 2016, 6, 4047-4063.

[38] W. Dong, Z. Shen, B. Peng, M. Gu, X. Zhou, B. Xiang, Y. Zhang, Sci. Rep. 2016, 6, 1-8.

[39] A. Corma, F. Llopis, J. B. Monton, S. Weller, J. Catal. 1993, 142, 97-109.

[40] J. Dijkmans, D. Gabriëls, M. Dusselier, F. de Clippel, P. Vanelderen, K. Houthoofd, A. Malfliet, Y. Pontikes, B. F. Sels, Green Chem. 2013, 15, 2777

[41] W. N. P. van der Graaff, G. Li, B. Mezari, E. J. M. Hensen, E. A. Pidko, ChemCatChem 2015, 7, 1152-1160.

[42] F. Liu, R. Wei, T. Wang, Fuel Process. Technol. 2018, 180, 114121.

[43] J. T. Scanlon, D. E. Willis, J. Chromatogr. Sci. 1985, 23, 333-340. 


\section{FULL PAPER}

Sn grafting on a dealuminated zeolite Beta resulted in a catalyst with both Brønsted and Lewis acidity, which was used for OME synthesis. The synergy of both acid sites resulted in a four-fold increase in turnover frequency and a reduction of by-product generation. The nature of the synergy is due to the interaction between $\mathrm{Sn}$ and formaldehyde.

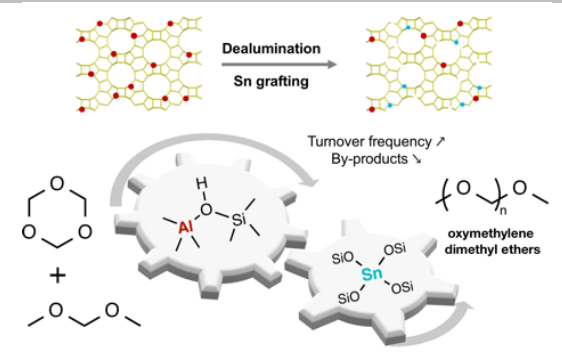

Christophe J. Baranowski, Maneka Roger, Ali M. Bahmanpour, Oliver Kröcher*

Page No. - Page No.

Nature of the synergy between Brønsted and Lewis acid sites in SnBeta zeolites for polyoxymethylene dimethyl ethers synthesis 